\title{
Is Informal English A True Gremline to International Students and Consequently Affecting Their Daily Life Communication With Native Speakers?
}

\author{
Samir A. Al Jumaily \\ Postgraduate Department- International Colleges of Islamic Science- London-UK \\ sbrother10@gmail.com
}

\begin{abstract}
This study is of twin purpose. First, it tries to investigate the linguistic difficulties encountered by international students studying in the UK in the use of Informal English and its effect on their daily life communication with native speakers. The second, it aims at finding out whether some other extra linguistic factors are responsible for this struggle of using or understanding the Informal English used by native speakers. In order to achieve the major objectives of the study fully, a survey has been designed to explore the main source and reasons behind these difficulties. Fifty, male and female, students studying in the UK, of various specializations, have been chosen carefully to participate in this survey. Accordingly, a statistical method/technique has been conducted to analyse, examine and describe the respondents' answers. A frequency count as well as a frequency rate is practised to assess the major source responsible for hindering these students to interact and communicate properly with native speakers whether in class environment or outdoor. Furthermore, the study has provided a brief account of how English being global along with some perspectives of Formal and Informal English as well as the differences between the two.
\end{abstract}

Keywords: Informal English, Formal English, gremlin, difficulties, international students, native speakers, survey

\section{Introduction}

\subsection{The problem}

International students studying in the UK may find it difficult for them to communicate properly with others, especially native speakers because of their lack of knowledge of the Informal English language terminology daily used. No surprise to get them hindered to maintain a sound interaction with native speakers communicatively and collaboratively, since they have not been earlier exposed to such variety in their homelands, along with being unable to develop a new interpersonal relationship, awareness of others' activities and information exchange. Accent difference could be a reason of difficulty. International students may find it difficult to understand their lecturers as well as other students of other nationalities, particularly at the beginning of their presence in the UK. There are some obstacles that naturally arise in a new country and academic environment, such as language issues which are immediately apparent. Because of the language limitations, it might not be easy for international student to fully understand what the professors say or what the professors want at the beginning, not to mention participating in class discussions. And, the language problem could also indirectly increase the workload burden of international students. (Gao,2008). Therefore, they might feel embarrassed.

The schooling educational system; primary, secondary, colleges and universities in the most of these students' countries concentrate in their curriculum on the formal language and formal settings, likewise the focus of teaching/learning is on the academic language and on its three main components; vocabulary, grammatical structure and functions. It differs entirely from the informal spoken language usually used outside the classroom, since it is formal, structural and culturally 
prestigious. This has led to the ignorance of informal form of English language, which is the most commonly used aspect of English language in everyday life activities in the UK, and which definitely reflects the authentic culture of the society. In addition, some other extra linguistic factors, such as homesick feeling, integration problems, family worries, finance, and culture shock could be responsible for these difficulties since students feel not encouraged/enthusiastic or willing to maintain proper communicative conversations with native speakers. (Keele University: 2017)

\subsection{Objectives of the study}

The main objectives of this study are to investigate whether Informal English is a true gremlin for international students, to diagnose the obstacles and difficulties impeding these students studying in the UK in using this language properly, and the reasons as well as the factors responsible for such difficulties. The study also tries to identify the nature and the effect of these often occur difficulties on their daily life communication with native speakers. Moreover, the study aims to inspect whether some extra linguistic factors could affect the proper use of informal language. Eventually, the study tries to positioning some solutions for the problems diagnosed.

\subsection{Significance of the study}

The findings of the study have redound to the significance of Informal English as a means daily communication between international students and native speakers in the UK as well as the role it plays in the international students' lives academically and socially. Therefore, the study has pointed out the significance of students being well prepared and having some knowledge of Informal English before heading to the UK. Such act will spare time and efforts which both, in fact, are crucial factors in in the international students' lives. Based on the participants' answers, the study advices these students to have some practical courses in Informal English in their home countries. Further, the researcher has taken the burden to achieve this study and tackle the problem due to not having previous studies dealt with the issue of Informal English and its importance for foreigners living or studying in the UK. Therefore, hopefully, this study paves the way for further studies relevant to this issue.

\subsection{Hypothesis}

It is believed that international students studying in the UK facing such difficulties due to various factors. One of them is that these students usually study, in their schools, the formal rules of English language and accordingly write and pronounce decent sentences, but when they are out of their classroom and away from the textbooks, they are encountering a type of language that breaks all these rules. Therefore, they start to struggle when they become exposed to such linguistic situations. The second factor could be due to the nature and characteristics of the idiomatic usage of the Informal English language. Communicating with the native speakers of English can be quite a confusing experience to international students. In English language, there are some phrasal expressions, which native speakers regularly use. This kind of expressions is called "idioms" or a proverb if they are longer. An idiom is "a group of words whose meaning is different from the meanings of individual words" (Hornby, 2015: 771).

The other factor that might be responsible for hindering the international students is the fast pace of informal exchanges and the lack of knowledge of slang which international students are unfamiliar with. Hornby (2015:1444) defines slang as "very informal words and expressions that are more common in spoken language, especially used by a particular group of people". 
Examples:

1. Think on your feet

Meaning - Adjusting quickly to changes and making fast decisions.

- A good salesman must be able to think on his feet to close the deal.

2. Get ducks in a row

Meaning - Getting your things well organized.

- To ensure a successful product launch, we must get our ducks in a row.

3. Full of beans

Meaning: To have loads of energy.

- All the children were full of beans at the party today. I couldn't get any of them to sit still!

4. Blighty

Meaning: an informal and typically affectionate term for Britain or England, chiefly as used by soldiers of World War I and World War II.

- There are blighty troops abroad.

5. Pear shaped

Meaning: This means something has become a disaster.

- I was trying to organise a surprise birthday party for her, but it's all gone pear shaped!

6. Piece of cake

Meaning: When someone is boasting or thinking something is extremely easy to do, he/she would use this.

- What did you think of the exam? I thought it was really difficult.

- No, it was a piece of cake!

7. Booboo

Meaning: A mistake.

- I made a booboo on the last question of the exam.

8. Kook

Meaning: A peculiar/crazy person.

- Stop acting like a kook.

9. Make waves

Meaning: cause problems.

- Teachers don't like students to make waves.

10. Quarterback

Meaning: leader

- James is the quarterback of the team.

\subsection{Procedure}

The sudy will tackle some perspectives regarding formal and informal language along with providing a brief account of the Informal English relying on the fact that language is an integral part of any culture, our primary source of communication and being the main instrument by which people understand each other's thoughts as well as their social life. It is the main intermediary tool for the conveyance of cultural understanding. In addition, the study will show the indispensable distinction between formal and informal learning settings debates about second language development. It is felt necessary and crucial to provide some literature about the power and dominance of English as a global language used worldwide.

A survey (questionnaire), which is the major source of data and highly based on qualitative reasearch method, has been tailored. Through analysing and describing the responses of the participants to this questionnaire, the feedback will explore and show the respondents' experiences of their interacting with native speakers and the difficulties they encounter in using Informal English 
language in their daily life communication. The questionnaire compromises a number of questions to specify the factors responsible for these difficulties. Respondents (students) are of different cultural backgrounds studying at a wide variety of fields in the UK. They are specialized in Architecture, Education, Business, Design, Literature, Drama and Music respectively. The students have been fully informed about the nature and purpose of the questionnaire and required to answer the questions objectively throughout their own personal experiences. A statistical study of the responses will be carried out in order to locate the trouble-spot and accordingly decide the difficulty rate. Eventually, the findings arrived at through the administration of the afore-mentioned questionnaire will be analysed, examined and described, and consequently suggesting and recommending especially tailored specimen strategy and plan in order to helping international students studying in the UK overcome their difficulties in the area of Informal English language use.

\section{English as a Global Language}

Language is our primary source of communication. It is the means people usually use to communicate and share ideas, thoughts and feelings with each other. It is a system definite to humans. It is an aspect of social practice which reflects our mental capability realized in speech articulation. This awesome faculty makes human beings superior to other species. "Language is a social energy, and our capacity for articulate speech is the key factor that makes us different from other species" (Hitchings, 2008:3).

English, which is the most international and worldwide spread language, is one of the Germanic languages. English to some extent is different from other Germanic languages (Dutch, Danish, Swedish, Icelandic, Norwegian, and Faroese). English language is much more prominent and distinguished compared to the other Germanic languages in its history and being exclusive in its status as a global dominant language in the 20th century. Although China and India are top world population of native speakers respectively, English is superior to the languages of these two countries in the number of people using English worldwide. There are probably more than one billion people who speak English either as a first or second language. All available evidence tells us that this number will go on growing. "Although Chines has more mother-tongue speakers, no language rivals English in the extent to which it is used across the world" (Dalby, 2004:166).

Crystal confirms that "The first significant step in the progress of English towards its status as a world language took place in the last decades of the 16th century. At that time, the number of mother-tongue English speakers in the world is thought to have been between five and seven million, almost all of them living within the British Isles. Between the end of the reign of Elizabeth I (1603) and the beginning of the reign of Elizabeth II (1952), this figure increased almost fiftyfold, to around 250 million, the majority (around four - fifths) living outside the British Isles" (2003:92).

There is no definite and official definition for a global or a world language. Otherwise, it refers to a language which is learned, taught and spoken internationally. A language is classified global according to the number of its native and second language speakers, geographical spread and its use as a main tool of communication in international organizations as well as in diplomatic relations. Likewise, a language gets the prestige of being global when it earns the official rank and education choice in a number of countries, which consequently is going to be used by other people as well and sounds superior to other languages used. Graddol states "The press release for the launch of the British Council's English 2000 project in 1995 summarised the position of English: World-wide, there are over 1,400 million people living in countries where English has official status. One out of five of the world's population speak English to some level of competence. Demand from the other four fifths is increasing. ... By the year 2000 it is estimated that over one billion people will be learning English. English is the main language of books, newspapers, airports and air-traffic control, 
international business and academic conferences, science technology, diplomacy, sport, international competitions, pop music and advertising" (2000:2).

In the process of foreign language learning/teaching, scholars distinguish between two types of languages functionally used. The first is a 'language of communication', and the second is a 'language of identification'. These two terms which are coined by the German applied linguist Werner Hüllen (1992) have been converted to lingua franca in the context of English language. It is believed that English can be used as a language of communication without being necessarily a language of identification (Fiedler, 2011:79). Therefore, a global language operating as a lingua franca permits people from diverse backgrounds and different countries to communicate and understand each other while their native languages are different. "Although English is not the language with the largest number of native or 'first' language speakers, it has become a lingua franca. A lingua franca can be defined as a language widely adopted for communication between two speakers whose native languages are different from each other's and where one or both speakers are using it as a 'second' language" (Harmer, 2001:1). Likewise, Graddol states "English increasingly acts as a lingua franca between non-native speakers. For example, if a German sales manager conducts business in China, English is likely to be used" (2000:13).

English has become the most widely spoken language. It has been used internationally for wide-ranging communication. "The spread of English in recent years is, by any criterion, a remarkable phenomenon" (Graddol, 2000:3). English has become part of the lives of a vast number of people and has helped to reduce a number of cultural barriers between countries. It has become the lingua franca of the present time. Bryson believes "English has become the most global of languages, the lingua franca of business, science, education, politics and pop music" (2009:2).

It is also believed that English is the closest language to be global. Its worldwide spread is much greater than anything accomplished historically such as Latin or French, for example. Its extension and spread was tremendous around many parts of the world. This vast growth of English language could mainly be attributed to the British and American trade and influence. "in the 19th century the British empire, with its distinctive mix of trade and cultural politics, consolidated the world position of English, creating a "language on which the sun never sets"" (Graddol, 2000:6). It is the native language of English-speaking colonies, and the second language of many other states that continue to need and use English as an international language. Worldwide, English rates as the most popular second language. Harmer states "Estimates of speaker numbers are somewhat variable. For example, Braj Kachru (1985) suggested between 320-380 million people spoke English as a first language, and anywhere between 250-350 million as a second language" (2001:1). For the time being, these numbers are not accurate as above mentioned. The number exceeds one billion and keeps on increasing. Accordingly, Crystal confirms "English is now the dominant or official language in over 75 territories, and is represented in every continent and in the three major oceansAtlantic (e.g. St Helena), Indian (e.g. Seychelles), and Pacific (e.g. Hawaii). It is this spread of representation which makes the application of the term 'world language' a reality" (2003:106).

"The idea of 'World English' was first paraded in the 1920s. Now it is a reality. Today there are more people using English as a second language than there are native speakers. English is spoken, with at least some degree of fluency, by more than a billion people. In truth the figure may be closer to double that, especially if we are prepared to accept competence in lieu of expertise" (Hitchings, 2008:339). English language has its own characteristics that make it superior to other languages. One of them is the range and quality of English literature throughout history which demonstrates to be the language of culture and elegance. As a result, it carries with it a certain authenticity, substance and significance that few other languages can match. "Most books on English imply in way or another that our language is superior to all others" (Bryson, 2009:8)

Scientifically speaking, the main factor for the foundation of a global language is being used and spoken by dominant powers such as military, business, economy, media and politics. 
"Languages become 'great' not because of the inherent qualities they may be deemed to have, but because of the political, military and intellectual force behind them" (Hitchings, 2008:9).

There are distinct reasons behind the prominent status of English and its linguistic global domination at present. The first reason is the expansion of British colonial power which has reached its highest point at the end of the 19th century. The second reason is the upsurge of the United States pioneering role in the world as a very important industrial, political, and economic power of the 20th century. "The position of English in the world today is thus the joint outcome of Britain's colonial expansion and the more recent activity of the US. Any substantial shift in the role of the US in the world is likely to have an impact on the use and attractiveness of the English language amongst those for whom it is not a first language" (Graddol, 2000:9).

Crystal is confident that "The USA contains nearly four times as many English mothertongue (EMT) speakers as the most important EMT nation (the UK), and these two countries comprise 70 per cent of all EMT speakers in the world (excluding creole varieties). Such dominance, with its political and economic underpinning, has given the Americans a controlling interest in the way the language is likely to develop" (2003:106). Therefore, "The continuing diffusion of English is, we can see, a consequence of capitalism and globalization, conflict and the Americanization of popular culture" (Hitchings, 2008:336). The dominance of the United States due to its political, military and economic powers had a great effect on English language status- to be recognized by the International Community as a global language. United States is considered the principal engine of global English. Because of its worldwide effect, many people from all over the world- Chinese, Brazilians, etc., are highly willing to have some knowledge of English language.

English is used increasingly as a language of international communication. Countries all around the world realized the pioneering role of this language. Thus, they have given it special status and start to study and practise it vastly although English is not their mother-tongue. Their academic institutions such as primary, secondary schools, colleges or universities, are teaching English language as a foreign language as well as using it as a medium of instruction. However, there will be no community who don't speak English in the future. "For members of smaller speech communities, the need to study foreign languages is strong, and English tops the list, as it occupies a dominant position in so many fields. Among these are diplomacy, trade, shipping, and the entertainment industry and youth culture. English is the lingua franca of computing and technology, of science and medicine" (Hitchings, 2008:336). Thus, the status of English as a Global Language at present time gives the impression that it is in an unbeatable position. It is the universal language of diplomacy and science, the principal language of internet, press, newspapers, books, travel, business and education.

\section{Some Perspectives of Formal and Informal English}

Formal and Informal English are two different styles, and each is used to serve different purposes. The choice and arrangement of words syntactically as well as syntagmatically vary between the two styles. They are two different styles or varieties. They are different in the word choice, usage, and grammatical structure. The former is used mainly in writing as well as official situations. It is used in official conversations and gatherings. It is free from the idiomatic and slang use that is not universally accepted or understood. The latter is the type of English that local communities use with all the idiomatic, slangy and quirky richness. It is used in everyday conversations and personal interactions as a casual style. It is used among friends and family members. Linguistically speaking, each language has its own entity, but through its history, the features of this entity are subject to many changes. Language in its very nature changes over time as cultures change and these changes may happen for political, social or cultural reasons. English language is not an exception. It has experienced many changes in various aspects. These changes are valid to words, Grammar, spelling, punctuation, and pronunciation. According to Hitchings "The 
fight is most often about 'the fundamental fact' of language identified by Whitney. Change happens. All living human languages alter: meanings shift, and so do pronunciations and grammatical structures. We may feel that the language we use is stable, but this is an illusion" (2011:4). Swan (2005:293) agrees with Hitchings in this respect stating "Languages change over time. Younger people adopt newer forms of expression, while older people often resist change; so even people who speak the same standard language do not speak it in exactly the same way".

Language is a social energy, and it is an integral part of any culture. Since people use language to communicate with each other, they are definitely practicing a kind of social relation and usually in such activity, it is presumed the concerns as well as the involvement of individuals or persons talking to is available. Therefore, different varieties or styles of language needed to be used depending on the social situation and the relationships with those who are involved. In addition, there are more linguistic choices to encounter the society social diversity.

The idea of language variety means our use of linguistic expressions is ruled by situational factors depending on how people from a particular region or profession speak and write in different situations. "To have only one style at our disposal, or to lack a sense of appropriateness in stylistic use, is disempowering and socially disturbing. Not only are we no longer in control of the situation in which we find ourselves, we soon discover that stylistic ineptitude is the first step on the road toward social exclusion" (Crystal, 2004:10). Similarly, Hitchings believes "Language is form, not substance; not communication, but a system of communication. . . We are the agents of change. The 'facts' of language are social: changes occur in a language because there are changes in the conditions under which the language is used" (2011:4). Dalby, in his turn, states "We need to speak to inform interest and persuade others. Doing this effectively often means using a style that is different from our written language" (2004: XIV).

Through the history of English language formality, informal language which refers to nonstandard English was inaccurately underestimated in comparison to the formal language which refers to Standard English. "No account of the history of English should ignore the whole of the language's formality range, but the informal levels have been seriously under-represented in the traditional accounts, partly because they have been so much associated with regional dialect speech" (Crystal, 2004:11). Similarly, "scholarship crystalized the standard form, often through inaccurate statements about non-standard forms, such as the assertion (in 1900) by Henry Sweet that 'Most of the present English dialects are so isolated in their development and so given over to disintegrating influences as to . . . throw little light on the development of English . .."' (Hitchings, 2011:207). Further, "Many people think that dialects are corrupted forms of a language, spoken by ignorant people who make mistakes because they have not learnt correct grammar. This is not all true. A standard language is not linguistically 'better' than other dialects; it is simply the dialect that has been adopted for official purposes such as government and education" (Swan, 2005:288).

The word 'Standard' implies the notion of using a language of standardised words and grammar which eliminates the use of informal features, like slang and incorrect grammar. "The standard language is not a homogenous phenomenon, internally consistent throughout in the way it uses pronunciation, spelling, grammar, vocabulary, and patterns of discourse. The common impression that such consistency exists, within an English-speaking community, derives from the fact that most of the written English we see around us is formal in character. It is English on its best behavior" (Crystal, 2004:7). Swan tries to identify the distinction between formal and informal language confirming "there are some words and structures which are mostly used in formal situations. When people are careful about how they express themselves: for example, in official notices, business letters or reports, meetings or conferences, or polite conversations with strangers. And some words and structures are mostly used in informal situations: for example, in conversations with friends, or letters to one's family. Writing is more often formal, and speech is more often informal" (2005:293). 
Spoken and written languages differ from each other mainly in language use and language structure. The grammar and vocabulary of speech is not the same as that of writing. Therefore, "Different standards should be applied to the spoken and written forms of the language. Yet, often people discussing the use of English fail to recognize the distinction. . . With reference to both speech and writing, most of us practise linguistic hygiene, brushing, or swabbing away what we see as pollutants - jargon, vulgarism, profanity, bad grammar and mispronunciations - and sometimes in the process replacing one kind of evil with another" (Hitchings, 2011:10). This view is not completely of use, since Standard English can be spoken in any regional accent. "To speak of someone using a 'regional' dialect is to mark oneself as a speaker of Standard English. But Standard British English ... is itself a (social) dialect. Its 'standard' nature is hard to define and is not regulated by an official body. In reality a language is a parcel of dialects. When I talk about the 'regional', it is with a heavy awareness that this is a fiction. All usage is regional; it is just that some regions are less readily identified, and other are more assertively stigmatized" (Ibid: 205).

It is important to recognize that when a new technological method of communication comes up, the whole way of communication will be greatly affected. Consequently, another form of language will be introduced. "The technologies that laid its foundation were originally developed as an aid to formal communication within the American military; the internet's precursor, the ARPANET, took its name from the US Department of defence's Advance Research Project Agency and grew briskly in the early 1970s" (Hitchings, 2011:290). The Internet, which allows people from all over the world to interact regularly and obviously, has significant consequences on language. It has led to the idea of the so-called global village. Also, the Internet has contributed in terminating the barriers among diverse communities around the world and has created a boundless society of speakers, categorized by special languages. Gooden mentions "Three or four new words and phrases make their debut in English every day. This phenomenon will only be intensified by modern mode of communication like blogging, texting and tweeting, all of which have greatly accelerated and broadened the spread of information" (2009:161). Similarly, Hitchings states "Electronic media have changed the rhythms of living. Barriers to communication have been removed: information flows more freely and inexpensively, . . . Furthermore, we are able to shape the information we exchange: everything can be digitized, and everything that has been digitized can be transformed" (2001:292).

Consequently, texting and messaging have increased the use of informal language via the internet and social networking sites like Twitter, Facebook and WhatsApp which are becoming increasingly important in our daily life communication. It sounds that Crystal is highly confident about the role of the internet in consolidating the effect and the increased use of the formal English when he says "I see the arrival of Netspeak as similarly enriching the range of communicative options available to us. And the Internet is going to record this linguistic diversity more fully and accurately than was ever possible before" (2004:241).

\section{Informal English and the International Student}

International students could understand the academic English, which is formal, relying on the way they have been studying English in their own countries, but they may struggle to understand and socialize with native speakers due to the high volume and speed of slang, dialect and colloquial English used in UK. Slang, vernacular and colloquial English do not always resemble the usage or vocabulary the students have learned in preparation for studying abroad. In other words, good knowledge of academic language may not suggest a good command and competence in informal communication. Therefore, international students could face a kind of communication problems and difficulties in engaging a proper informal interaction. Although some international students have language skills, they may face hard times due to cultural differences. British cultural aspects, patterns and terminology might be problematic since it is a representation of another cultural community 
making it difficult for them to comprehend informal English conversations. As a result, insufficient command and discomfort of the informal target language may be experienced within social contexts and consequently international students may feel incompetent and apprehensive to communicate with native speakers.

Therefore, informal interaction may be a challenging factor for international students beyond classes; whereas in the class environment students are at relief since the medium of instruction is Formal English. They may find themselves not familiar with the vocabulary of the Informal English language used in the UK as well as the wide-range use of idiomatic phrases and slangs by native speakers. They communicate well in formal situations but have difficulty with the common conversation takes place outdoor. For most international students English is just a non-native language. English is considered as a foreign language rather than a second language in this context and is not used as a medium of communication or for other purposes in society. Consequently, international students' limitation of a decent knowledge of English cultural terms, make them feel misled in English-based social activities. In addition, the culture difference between native speakers and international students may be a hampering factor of informal communication engagement and social interaction.

English language has many local dialects and accents, and every minor locality of England has its own distinctiveness of accent and vocabulary. These dialects have developed and changed over time. Hitchings tries "to clarify that accent and dialect are different. . Accent is only one feature of a dialect, which is a variety of language that also differs from other varieties in its vocabulary and grammar. Moreover, while a dialect has its own slang, it is wrong to say that dialects are slang" (2011:192). These various features of the language are the most distinguished characteristics of daily usage of English language by native speakers and have been measured as an image of very nature of the society of which international students have no idea. Everyday English mostly consists of non-standard or informal features of the language: common, colloquial, slang and idiom. Idiomatic phrases and slang are widely used in the UK. Regretfully, international students have not often learned such aspects of English in their formal language learning environment. Therefore, they are limited and not in ease with colloquial, spontaneous conversation, and find it challenging to recognise certain conversational principles. Informal language features' usage is the main instrument for everyday settings. It represents the notion of community social life and its culture. Informal language is the language that states the tangible realities of the people around us.

Worldwide, formal English learning is achieved in school and conducted under a teacher's guidance. It is believed that international students can learn many aspects of knowledge related to everyday English by means of self-study in home and other possible channels, like watching English movies and through interaction with the native speakers or exposure to authentic language input through technology to practice English in listening and speaking. By such activities international students may master the everyday language use since it is rich with slang, idioms, and informal language patterns.

\section{Description of the Survey}

Generally speaking, a survey is a tool or method usually used to gather information or data as reported by participants in order to examine and understand the opinions of a group of people. Surveys are used in various fields of study. They are realized in two forms; either a questionnaire or an interview. They are usually used to achieve various purposes and could be conducted through a printed questionnaire, over the telephone, by mail, in person, by diskette, or on the web (https://www.hr-survey.com/WhatIs.htm). Questionnaires usually contain a list of questions designed and administered to investigate respondents' perspectives about a specific issue. There are two types of questionnaire; namely, the unstructured one in which the respondents express themselves in any 
course of interest they think through and the way they consider, and the structured in which the respondents fill out the survey on their particular questions depending on their own convenience and experience. Questionnaires, mainly and regularly, use closed-ended questions which are followed by response options in order to limit the respondents' answers to these options.

The two major methods practiced to conduct a questionnaire are the qualitative and the quantitative. The former is considered the most excellent one in providing a wide range of detailed information and explanation, whereas the latter supplies information that is entirely precise and detailed depending on gathering statistic and numeric data.

The survey undertaking in this study is a form of qualitative questionnaire containing 10 closed-ended questions. The number of the participants is 50, both male and female. In order to avoid any misunderstanding, the respondents have got a clear explanation about the content of the questionnaire. They are advised to maintain their answers to the point in order to meet and achieve the main objective of this study.

\subsection{Criteria of Selecting the Respondents}

Care has been taken to ensure that all the respondents are of different nationalities, cultures and linguistic backgrounds and that no erroneous factors are allowed to affect the results of the questionnaire. All the participants are studying in the UK in a wide variety of fields, such as Architecture, Medicine, Education, Business, Design, Literature, Linguistics, and Music. Participants have been highly enthusiastic and willing to do the job objectively. They never get together, and the job done individually. No time limit considered. They have got the required time to achieve the assignment fully and honestly. Prior to answering the questionnaire, respondents encouraged to ask for any explanation regarding the form of the questionnaire, and were given the instructions as to the way to perform the job. Moreover, they have been asked the following questions before taking the survey in order to avoid any erroneous factor which could affect the results:

1. Have you had earlier any course in any type of English outside school or abroad?

2. Have you ever been to an English-speaking country before coming to the UK?

3. Have you ever attended any class of Informal English?

4. Do you communicate with friends through social media using Informal English?

5. Have you been taught by native speakers of English who use slang English?

6. Do both or one of your parents from an English-speaking country?

None of the participants answered with YES, a fact which ensured the survey's objectivity as well as the absence of any sort of interference with the results of the survey so designed.

\subsection{Objectives of the Survey}

The survey aims at:

1. diagnosing the reasons relative to the daily life communication difficulties encountering international students studying in the UK through their experiences of interacting with English native speakers and their struggle of using and understanding Informal English,

2. finding out through accounting for the answers obtained, and through a statistical study of their frequency which factor is mainly responsible for getting international students hindered from efficiently communicating with native speakers in the UK, and whether some extra-linguistic factors are involved,

3. finding out through frequency count of the answers as well as the frequency rate of the difficulties or problems the major source responsible. 


\subsection{Objectivity of the Survey}

The survey is an objective one aimed at assessing the cause of the difficulties and problems facing international students studying in the UK and the factors behind these difficulties in using Informal English and its effect on their daily life communication with native speakers. All the respondents are adults, both male and female. They are all asked to perform the same task and supplied with the necessary information and instructions. As mentioned earlier, they got the opportunity to ask any question related to the questionnaire along with giving them the time required to achieve the assignment fully and objectively. Further, the survey is objective since all the respondents have provided the same negative answers to the above seven questions. This ensures that no erroneous factors have affected the respondents' answers.

\subsection{Method of Analysing, Describing and Scoring the Results of the Survey}

As earlier mentioned, the survey is anticipated to inspect through the respondents' feedback, the major factors responsible for hindering international students studying in the UK form achieving a sound interact and communication with native speakers. It is also expected through frequency counts of the respondents' answers to spot the difficulty range of each item in the survey by summing up the identical answers. An analysis of the answers will make it possible to detect and investigate the reasons underlying these difficulties. The higher percentage of similar answers will certainly reflect the top responsible factor of the difficulties; in the sense, the more the number of the respondents giving the same answer, the more difficult the factor is. Then, the difficulty rate will be considered downwise. If scoring of the responses shows that only a small number of the respondents provide the same answer, this may be attributed to one or more than one of a variety of factors.

It is obvious that the type of English used and taught in the international students' homelands' schools is the Formal English. Therefore, it is the rules of this variety of English that the students have mastered and well knowledgeable about. The respondents' answers for each item of the questionnaire is scored independently in order to find out the most serious issue behind each difficulty. The number of the similar answers will determine the relative difficulty rate of each item. The participants are all international students of different backgrounds studied Formal English at their schools. They received instruction in English from supposedly equal teachers in their level of training and used almost the same approach. Eventually, the answers are tabulated and arranged in accordance with their frequency of occurrence. This procedure will help arrange the answers their potential rate of similarity, and pointed out above a comparison of counts of the responses in every item versus every other item will help decide the rate of each difficulty. The figures in the table show the number of the respondents choosing each item of the questionnaire and represent the percentage to be secured through every frequency count made here, since the number of the participants is 50 and the items of the questionnaire is 20 . This procedure of tabulation is intentionally followed to facilitate attaining the results of the statistical study and to achieve accuracy.

\subsubsection{Accounting for the Respondents' Answers}

A glance at the table shows clearly the respondents' experience about the level and the source of the difficulty of each factor according to the frequency of their answers. The vast majority of the respondents agree that they communicate with their nationals using their native language. $96 \%$ of the respondents have answered with YES, while only $4 \%$ have said NO for question \#9 in the questionnaire. A fact which indicates that these students are like isolating themselves from native speakers, and this will definitely result in losing the chance to get them exposed to Informal English language input. The difference between Formal English learnt at schools and Informal English daily spoken is also a major obstacle to the international students studying in the UK to interact or 
communicate fully with native speakers. This proves the hypothesis made that informal communication is a highly challenging issue since the schools' curriculum is focusing on formal language settings and not the informal ones of which students are unfamiliar. $94 \%$ of the students have answered with YES, while 6\% have said NO for question \#1. Therefore, these students are at relief in formal communicative situations or class environment, whereas they find themselves inefficient and struggling in achieving proper outdoor common conversations. In line with this and as the answers for question \#8 show, respondents affirm that they communicate with their classmates using Formal English. A fact which still confirms that these students are at ease in such communicative situations, since they have some knowledge of this variety. Therefore, $92 \%$ have answered with YES and only $8 \%$ with NO. This really again supports the hypothesis made that these students could successfully achieve official conversations and fail to achieve informal ones. This shows that although the respondents are of different cultural backgrounds, they can communicate fully and easily with each other using Formal English, while they are facing the same communicative problem with native speakers using Informal English. Therefore, they have something common and unwanted which may consequently affect and kill the opportunity to improve their learning skills of Informal English terminology.

Respondents, according to their answers for question \#6, prefer to have some courses, at their homelands, in Informal English before coming to the UK. These students believe that the vocabulary difference between the Formal and Informal English is a confusing factor hindering them from interacting with native speakers. These students assure that if they have had courses in Informal English before coming to the UK, they would have felt confident to start conversing beyond class environment owing to the knowledge they had already acquired in this respect. By such knowledge, it is meant the vocabulary and nature of the Informal English. Thus, having such sort of knowledge, would make it easier for them to integrate and lead a smooth peaceful daily conversations. The percentage record of this question is quite identical to that of question \#8. English language centres, offering such courses, could help a lot, if they were available in the students' countries.

According to the respondents' answers for question \#2, they are not familiar with the idiomatic phrases. This lack of familiarity of idiomatic phrases may be relatively a barrier to achieve informal communication. In daily life communication, native speakers usually and continuously use a lot of idioms that often make it hard for international students to grasp and understand. Thus, communication with native speakers in the UK can be quite a confusing experience to international students. These students have not been in tangible proximity with the informal form of the language, and their lack of familiarity with idiomatic phrases may hamper them of affirmative informal communication. The percentage for this question is $88 \%$ YES and $12 \%$ NO.

The respondents' answers for question \#3 are almost matching that of question \#2 and show the percentage of $86 \%$ YES and $14 \%$ NO, which indicates that it is not only unfamiliarity of idiomatic phrases that shapes the source of difficulty, but some other factors as well. So, in order for these students to get familiar with the terminology as well as the nature of Informal English, they are required to engage and get exposed to Informal English language input.

Respondents may be desperate and under stress when using colloquial terminology, specifically when getting involved in spontaneous conversations. It is well known that Informal English including colloquial, slang and dialect usage which contain fix-word collocations, phrasal verbs, idioms, proverbs as well as many regional differences in vocabulary usage. This will definitely affect international students' daily communication with native speakers. Therefore, it is anticipated that these students face serious problems and difficulties in this respect, and may hold negative attitudes towards Informal English. Consequently, $80 \%$ of the respondents have answered with YES, whereas $20 \%$ have said NO for question \#5.

Since international students are profoundly adhered to the formal form of English language, they are keen to maintain the rules and structure of this variety. Therefore, they find the informality 
in the electronic communicative procedure, specifically through the social media, has led to the inaccurate use of the systematic rules of English particularly in grammar and spelling. Their answers for question \#10 reflects this view which is represented in the percentage of 74\% YES and $26 \%$ NO. This, in fact, gives the impression that all their electronic communications follow the formal style, whereas the social media are highly considerable tools to practice the informal language.

Linguistically speaking, language is part of the culture of any society. Some believe that culture difference is a source of difficulty for international students studying in the UK. Some of these students are extremely influenced by their own culture and cannot easily adjust to the new culture. They may encounter a number of difficulties, specifically at the beginning, related to the academic environments as well as social interactions. International students may suffer to establish a reasonable social interaction and making friendship with native speakers. They are expected to struggle when sharing various topics, views and interests with native speakers. Therefore, culture difference represents a type of extra-linguistic factor responsible for the difficulties which consequently driving international students to interact with people from their own countries as earlier mentioned, and just few of them contribute and participate in activities or students' societies at the university and other English social life issues. This could be well realized in their response percentage of $66 \%$ YES and 34\% NO for question \#4.

For question \#7, 8\% of the students have confirmed their use of Informal English in their communications with classmates. This is one more fact that shows their unwillingness to use this variety. $92 \%$ of these students communicate with classmates and native speakers using the formal one which has been earlier confirmed due to their answers for question \#8. This formula of the dichotomy of the results of question \#7 and 8 proves the great objectivity of the questionnaire used as well as the hypothesis made, since exactly the opposite results obtained between the YES and NO. Thus, they often choose to interact with fellow speakers using their own native language or using the formal one to communicate with speakers of other languages. They may find it easier for them to communicate with other international students using Formal English, since they share the common knowledge of this variety already acquired at their homelands schools. Again, such act will give the impression that these students highly tend to use the Formal English and avoid using the Informal English owing to be hesitated, under stress, unconfident and embarrassed for fear that they misunderstand others informal communications.

\section{Summary of the findings, conclusions and recommendations}

The study has concluded that international students almost always use their mother tongue when communicating with each other. Such conduct certainly keeps them isolated and lose the opportunity to get exposed to the Informal English input, while it is well known that language is usually acquired through practice and communication with the native speakers of that language. Therefore, these students get hindered to communicate properly with native speakers in the UK. Moreover, talking to classmates of other nationalities using the Formal English learnt at schools is the second factor responsible for shaping the difficulties facing international students, and consequently hampering them to achieve daily life conversations duly. Thus, our concern whether Informal English is a sort of gremlin to these students is true specifically at the first years of their study. In order for international students to overcome this problem, it is recommended that they should stop using their mother language with their nationals as well as Formal English with classmates of other nationalities, and try to focus on using the one daily used by native speakers. Such act will make the chance available for them to gain some linguistic knowledge through communication/practice and consequently improve their skills of using informal language.

It is also found that the difference between the vocabularies of Formal English learnt at schools and Informal English, which these students are not familiar with, is a major factor 
responsible for the difficulties encountering international students to maintain sound communicative conversations. Further, the idiomatic phrases as well as the colloquial terminology of which students are unfamiliar is a true barrier for them particularly when they get involved in spontaneous conversations with native speaker whose speech is rich with such phrases they often daily use. Thus, informal communication is a highly challenging issue since the school's curriculum is focusing on formal language settings and no consideration set for engaging students in Informal English courses. Since these students are extremely willing to have such courses, it is recommended that schools should create, adapt and add these courses to their curricula. Public and private English language centres could also help and play a major role in organizing the required courses. Certainly, such courses will equip international students with the tools and knowledge required, and drive them away from stress and hesitation in communicating with native speakers the time they arrive the UK.

The study has arrived at the fact that many of these students are intolerant of violating the systematic rules of English, specifically in grammar and spelling through the modern electronic communication tools. This shows their tendency to use the formal one which they have used to practice in their communications. But, this gives the impression that they didn't try to learn some informal aspects of English language from such electronic tools.

It has also been found that culture difference is a factor that makes international students not easily adapt to the new cultural environment, specifically at the beginning of their academic and social life. Consequently, they try to group with their nationals in order to avoid embarrassment, stress and being unconfident. This is an extra-linguistic factor responsible for some difficulties. In order to avoid the struggle with language usage and insufficient adjustment, international students are recommended to be open-minded, positive and keep in touch with British nationals, drop negative attitudes, and take part in all students' academic and social activities at school and outdoor. On the other hand, academic institutions, such as universities, need to assist international students to overcome those difficulties arise from cultural and linguistic differences. Principles and guidelines for structuring formal as well as informal curricular activities and services are suggested. They are also required to motivate students and ask teachers to take responsibility and working on developing intercultural engagement and understandings as well as being concerned enough to international students. Eventually, we recommend that the authorities concerned work on creating an internationalized curriculum that could consequently develop intercultural competencies in international students. Thus, students across institutions are required to get engaged and follow a specific internationalized agenda in order to gradually improve the interaction between native speakers and international students.

\section{References:}

[1] Bryson, Bill, Mother Tongue. The story of the English Language. London: Clays Ltd, (2009)

[2] Crystal. David, The Cambridge Encyclopaedia of English Language. $2^{\text {nd }}$ Edition, Saronno: Rotolito Lombrdo, (2003)

[3] Crystal. David, Language and the Internet, London: Cambridge University Press, (2004)

[4] Dalby. Andrew, Dictionary of Languages, London: A\&C Black Publisher Ltd, (2004)

[5] Fiedler. Sabine, English as a lingua franca-a native-culture-free code? Language of communication vs. language of identification, Apples - Journal of Applied Language Studies, 5(3)(2011), 79-97

[6] Gooden. Philip, The Story of English, London: Quercus Publishing, (2009)

[7] Graddol. David., The future of English, London: The British Council, (2000) 
[8] Harmer. Jeremy, The Practice of English Language Teaching, Malaysia: Pearson Education Limited, (2001)

[9] Hitchings. Henry, The Secret Life of Words, London: A Hachette Liver Company, (2008)

[10] Hitchings. Henry, The Languages wars, A History of Proper English, London: An Hachette UK Company, (2011)

[11] Hornby. Albert Sydney, Oxford Advanced Learner's Dictionary. London: Oxford University Press, (2015)

[12] Swan. Michael, Practical English Usage, London: Oxford University Press, (2005)

[13] Gao. Fangfang, Academic Difficulties, (2008), Retrieved from: http://plaza.ufl.edu/ffgao/mmc5015/final/academic.html

[14] Keele University, Counselling and Mental Health Support: Common Difficulties for International Students, (2017), Retrieved from: www.keele.ac.uk/studentcounselling/thingsnotgoingright/commonproblemsforinternationalstudents/

[15] What is a Survey? Retrieved from: https://www.hr-survey.com /WhatIs.html

Appendix I. Items of the questionnaire:

1. Do you think that informal English is quite different than that you have learnt at school?

2. Do think that you are not familiar with idiomatic phrases?

3. Do you think that you are entirely unfamiliar with Informal English?

4. Do you think that culture difference is a hampering factor in one way or another?

5. Do you think that you are not in ease and under stress when using colloquial, spontaneous daily conversations with native speakers, and accordingly holding a negative attitude?

6. Do you think having courses in Informal English before coming to the UK is necessary and helpful?

7. Do you communicate with your classmates using Informal English?

8. Do you communicate with your classmates using Formal English?

9. Do you communicate with your nationals using your own native language?

10. Do you believe the use of informality has led to the inaccurate use of the systematic rules of English such as grammar and spelling?

\section{Appendix II}

Table 1: Difficulty Rate of Focal Elements

\begin{tabular}{|c|c|c|c|c|}
\hline \multirow[t]{2}{*}{ Item No. } & \multirow[t]{2}{*}{ Point of Focus } & \multicolumn{2}{|c|}{ Average answer percentage } & \multirow{2}{*}{$\begin{array}{l}\text { Rate of Reason } \\
\text { of Difficulty }\end{array}$} \\
\hline & & YES & $\mathrm{NO}$ & \\
\hline 1 & Informal English is different than that leant at school & $94 \%$ & $6 \%$ & 2 \\
\hline 2 & Lack of familiarity with idiomatic phrases & $88 \%$ & $22 \%$ & 4 \\
\hline 3 & Whether entirely unfamiliar with Informal English & $86 \%$ & $14 \%$ & 5 \\
\hline 4 & Culture difference & $66 \%$ & $34 \%$ & 8 \\
\hline 5 & $\begin{array}{l}\text { Not in ease when using colloquial, spontaneous } \\
\text { conversations }\end{array}$ & $80 \%$ & $20 \%$ & 6 \\
\hline 6 & $\begin{array}{l}\text { Courses in Informal English are not available before } \\
\text { coming to the UK }\end{array}$ & $92 \%$ & $8 \%$ & 3 \\
\hline 7 & Communicating with classmates using Informal English & $8 \%$ & $92 \%$ & 9 \\
\hline 8 & Communicating with classmates using formal English & $92 \%$ & $8 \%$ & 3 \\
\hline 9 & $\begin{array}{l}\text { Communicating with their nationals using mother } \\
\text { language }\end{array}$ & $96 \%$ & $4 \%$ & 1 \\
\hline 10 & $\begin{array}{l}\text { Whether the use of informality in electronic } \\
\text { communication leads to inaccurate grammar and spelling }\end{array}$ & $74 \%$ & $26 \%$ & 7 \\
\hline
\end{tabular}

